\title{
Priorities and Preferences in Water Quality Management - a Case Study of the Alsterån River Basin
}

\section{Kristina $\mathrm{Ek}^{1}$ (D) $\cdot$ Lars Persson ${ }^{2}$}

Received: 7 May 2019 / Accepted: 17 November 2019/

Published online: 16 December 2019

(C) The Author(s) 2019

\begin{abstract}
Sweden is a decentralised country where local managers, who are key actors in water management, often deal with relatively difficult prioritisations, tradeoffs and conflicting goals. Many of these challenges relate to the effective implementation of the European Union Water Framework Directive. As an input to these challenges, the present paper elicits and analyses local and semi-local citizens' preferences for water quality attributes related to the European Water Framework directive in a river basin located in southeast of Sweden. Based on a choice experiment tailored to the case study area, the paper analyses preferences for selected attributes based on real criteria for ecological water status in the implementation of the directive. The target population lives in the municipalities through which the river passes, or in municipalities neighbouring those. Despite this spatial proximity to the river, the analysis reveals limited knowledge and interest in matters related to the environmental quality of the river. There is no evidence that preferences differ between respondents with regard to experience or knowledge about the water basin, nor with regard to recreational habits in the area. These results offer input to local water management by providing information about preferences for explicit water quality attributes.
\end{abstract}

Keywords Choice experiment · Water quality attributes · European Union Water Framework Directive

Kristina Ek

kristina.ek@1tu.se

Lars Persson

lars.persson@umu.se

1 Luleå University of Technology, Economics Unit, SE-97187 Luleå, Sweden

2 Department of Economics, Centre for Environmental and Resource Economics, Umeå School of Business, Economics and Statistics, Umeå University, SE-90187 Umeå, Sweden 


\section{Introduction}

The European Union Water Framework Directive emphasises public participation and economic principles, but also that management should be organized by the natural logic of water catchment areas, rather than by existing administrative borders (EC 2000/60). As Sweden is a decentralised country, with substantial autonomy and authority being devolved to local municipal level, local decision makers and officials are key actors in the directive's implementation. The purpose of the study, therefore, is to elicit local and semi-local citizens' preferences for water quality attributes explicitly related to the directive. Thus, the paper analyses how the local and semi-local population value important criteria for low, moderate, good and high ecological status in the case study area, namely the Alsterån River Basin in the southeast of Sweden. By this approach, the study focuses on preferences for characteristic directive attributes and explicitly highlights tradeoffs across them. The methodological approach to achieve the study's aims is a choice experiment where hypothetical alternatives are based on modified versions of the actual criteria for different levels of water status used in the implementation of the directive in the area (and elsewhere in Sweden). The identified population potentially holds both use and non-use values, and in the choices between alternatives respondents state their preferences for given attributes. By studying the choices, we are able to assess both the economic values and the potential trade-offs between relevant water quality criteria.

The management of water bodies is not only a spatial issue: it also involves the respective standards defining their ecological status. Because several criteria characterise these standards, the tradeoff between goals needs to be considered in the water body's practical management. Moreover, since it is unlikely that all criteria defining the quality standards will be reached simultaneously, decision-makers need to prioritise some of these criteria above others. The challenge here is that the directive implicitly gives equal weight to each criterion (they are all absolute) and does not guide policy makers on how to prioritise them. ${ }^{1}$

Sweden has many relatively small municipalities (in number of citizens) and local decision structures. These local authorities and decision makers often work simultaneously with many different issues - sometimes with conflicting policy goals (Söderberg 2016). Arguably, this aspect of practical water management gains additional significance given the directive's requirement for public participation and economic principles. Thus, the environmental values held by Sweden's citizens constitutes an important input for policy makers and authorities responsible for the management and implementation of water quality standards. This is where the present study contributes with its explicit focus on public preferences for attributes closely linked to the directive.

At the time of the study in 2014, the Alsterån River Basin had not yet reached good status and there was still much work to be done. While the study may guide policy makers to better consider cost effectiveness of different measures, it also contributes with advice for policymakers related to their distributional dimensions. Specifically, the paper elaborates on socioeconomic factors underlying the respondents' willingness to pay to avoid the status quo situation, as well as for changes in each water quality attribute. Taking all of these factors into account will increase the legitimacy, public acceptance and implementation of measures to give effect to the directive.

\footnotetext{
${ }^{1}$ It is only possible to define less stringent environmental objectives if technical infeasibility or disproportional high costs can be proved (see e.g. Klauer et al. 2016). A choice experiment like in this paper serves as input also in such an analysis.
} 
Previous studies have also applied stated preference techniques to assess the willingness to pay for policies to improve the ecological status of water quality to meet the requirements of the directive. For instance, Eggert and Olsson (2009) apply a choice experiment in their study on marine water quality and focus on the trade-offs in practical policymaking. The attributes in their study related to bathing water, fishing possibilities (cod stock) and biodiversity levels. They found that marginal willingness-to-pay estimates were higher for improved fish availability and avoiding biodiversity deterioration than for bathing water standard. Kosenius and Ollikainen (2015) show that the preferences for improved water quality in coastal marine ecosystems differ significantly across the residents of Finland, Sweden and Lithuania. There are also studies on the ecological status of rivers (e.g. Hanley et al. 2006b; Loomis et al. 2000; Loomis 2000). Although the literature on willingness to pay for water quality attributes is rather extensive, knowledge about directive-related attributes in a Swedish context is scarcer. In the Swedish case of inland waters and rivers, the literature is limited and focuses mainly on the impacts of hydropower generation. For example, Kataria (2009) applied a choice experiment approach to elicit preferences for improved environmental quality in hydropower -regulated ${ }^{\text {regulated }}$ rivers in Sweden. Kataria reported that people value improvements in river-margin vegetation and erosion, species richness for the benthic invertebrates and improved fish stock. Sundqvist (2002) also applied a choice experiment to estimate the value of reducing the environmental impacts from hydropower generation and his findings suggest that, in addition to low costs, erosion and fish life improvement were considered important. Håkansson (2009) evaluated the societal benefits of increasing salmon population at the cost of reducing hydropower production in a Swedish river, she found that the costs of reduced electricity production would outweigh the benefits of increasing salmon populations. There are also studies estimating the willingness to pay for measures aimed at improving fish passages to reduce the negative impacts of hydropower generation (e.g. King et al. 2016; Paulrud and Laitila 2013). Our study complements this body of literature and fills a relevant gap because, rather than focusing on the impacts of hydropower generation, we focus on the criteria set up by the water authorities in respect of the good ecological status of the Alsterån River Basin itself.

The remainder of the paper is organised as follows. Section 2 describes the case study and the survey design, while section 3 presents survey responses and econometric results. Section 4 concludes and discusses the policy implications.

\section{Method and Data}

\subsection{Selection of Method, Study Area and Sample Population}

Since the attributes characterising water quality are multidimensional, a choice experiment approach was considered appropriate. In terms of water quality and the implementation of the directive, the choice experiment enables one to estimate the value people attach to the quality attributes of a water body, such as its clarity, the number of fish species, amount of benthic fauna it supports, availability and its physical appearance. However, while this method potentially captures a wide variety of characteristics, the researcher must consider both the relevance of the outcome from a policy perspective and the capacity of the respondents to deal with the complexity of the issues being investigated. The attributes and levels presented in the choice experiment need to be understandable and relevant; the hypothetical choice should be 
perceived as realistic and meaningful for non-scientists; and the outcome should be useful for scientists and policy makers alike (Lehtoranta et al. 2017). People in general cannot be expected to be familiar with ecological concepts or changes in ecological quality and simplified communication is necessary. Indeed, many stated preference studies have been criticised for defining and describing ecological changes in rather vague or even arbitrary measurement units (see e.g. Johnston et al. 2012; Zhao et al. 2013 for a discussion about ecological indicators and content validity in stated preference studies). Attribute levels should be related to measurable ecological conditions, whereas oversimplification may reduce content validity (Bateman et al. 2002; Johnston and Duke 2007; Johnston et al. 2012; Mitchell and Carson 1989). ${ }^{2}$ The present paper contributes in this dimension via its close link to local and practical policy making in the case study area.

The study also needed to ensure that the population targeted for the study was relevant in respect of the directives implementation in the Alsterån River Basin. Thus, preferences were elicited from residents living close to, or semi-close to, the river basin. These respondents included people living in municipalities through which the river flows, as well as municipalities neighbouring those (municipalities within a geographic circle with a radius of about $50 \mathrm{~km}$ ). The motive for the definition of the study area is the administrative structure prevalent for water management, i.e. river basins.

The identified population potentially holds both use values and non-use values. The population is likely to include also people with limited knowledge of, or interest in, the river, which makes it possible to study differences in preferences related to knowledge, recreation habits and familiarity. From the policy maker's perspective, this is of interest since it points at the difficult task of considering not only the preferences of the most involved inhabitants but also of "common people" in the area. In case the results indicate large differences between people living close to the river and/or regularly visits the river catchment area and those who do not, the implication would be that the scope for benefit transfers is limited. On the other hand, if it turns out that preferences for the specified attributes are not highly dependent on distance, recreational habits etc., the results may apply to other (similar) river basins. From a practical policy perspective, the latter results would be valuable since they could potentially guide policy makers in a wider context than this case study specifically (Hanley et al. 2006a).

\subsection{Data Collection and the Choice Experiment}

Data was collected by implementing a questionnaire. Respondents were asked to choose between different alternatives defining different expected statuses for the Alsterån River Basin by the year 2020. Each choice set was defined as a choice among three alternatives, of which one represented the water body's ecological status quo at the time. The respondents were informed that a certain European Union Directive stated that all EU waters were required to be of good quality, and that important ecological criteria for the status of the Alsterån River Basin included the level and variety of fish and benthic fauna species, as well as water clarity.

The catchment area consists of the Alsterån River itself as well as smaller water bodies. To make the choice task comprehendible to respondents, the average status for the whole catchment was described. The survey also collected information regarding respondents' interest, knowledge and beliefs about the water status of the river.

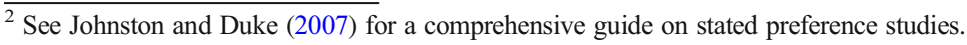


Respondents were first informed of the current status of the river with respect to its quality attributes and possible changes to that status. Focus was on constructing relevant and realistic alternatives to provide guidance for local authorities and policy makers in their tradeoffs when prioritising across measures.

The attribute levels for biodiversity correspond to the ecological criteria used, which differ from many valuation studies that are less explicitly related to the directive (Birol et al. 2006; Carlsson et al. 2003; Hanley et al. 2006b; Håkansson et al. 2016; Kosenius and Ollikainen 2015; McGonagle and Swallow 2005). Thus, the approach taken by this study was to consider relevant and common factors relating to the ecological quality of the whole river basin, these factors were then translated to attribute levels. The definition and formulation of the alternatives and their corresponding levels were developed in close collaboration with local expertise at the Water Authority (Samuelsson 2012), and supported by local reports and policy documents (e.g. Water Authorities 2010), together with deliberations in focus groups and pre-tests. As a result, the study selected three levels to define the attribute Water clarity: Clear, Moderate and Turbid and colored - where Moderate describes the status quo. Four different levels define the Fish - variety of species attribute: Very high, High, Moderate and Low where Moderate describes the status quo. Three levels define the Benthic fauna variety of species: Very high, High and Moderate - where High describes the status quo. Table 1 summarises the three attributes and their respective levels, along with the monthly cost (until 2020). In the questionnaire, respondents were given this information prior to the choice tasks.

The level of each attribute corresponds to the criteria used by the water authorities for Low, Moderate, Good (High) and High (Very high) water quality. During the pre-tests, some respondents expressed uncertainty about how to understand the difference and relative ordering of "Good" and "High" water status. To reduce such uncertainty, these two status levels of water quality were instead called High (instead of Good) and Very high (instead of High) water status.

Table 1 Quality attributes and levels

\begin{tabular}{|c|c|}
\hline Quality attribute & Level of quality \\
\hline Water clarity & $\begin{array}{l}\text { - Clear: Very little turbidity; water has little color and is oxygen rich } \\
\text { - Moderate: Mildly turbidity; water is more colored and/or less oxygen rich } \\
\text { - Turbid and coloured: Very turbid; water is highly colored and/or anoxic } \\
\text { or almost anoxic }\end{array}$ \\
\hline Fish - variety of species & $\begin{array}{l}\text { - Very high: Many sea-migrating fish (salmon, trout), brook trout and } \\
\text { other fish species (pike, minnow, sculpin, burbot and dace). } \\
\text { - High: Some sea-migrating fish and viable population of brook trout } \\
\text { and other fish } \\
\text { - Moderate: No sea-migrating fish, but possibly brook trout and viable } \\
\text { populations of other fish; implanted fish species may exist } \\
\text { - Low: Low stocks of all fish species, but some resistant fish species } \\
\text { (e.g. tench and bream); implanted fish species may exist. }\end{array}$ \\
\hline Benthic fauna - variety of species & $\begin{array}{l}\text { - Very high: A large number of rare species (e.g. rare water beetles } \\
\text { and dragon flies) } \\
\text { - High: A smaller number of rare species } \\
\text { - Moderate: No rare species but some resistant species may exist }\end{array}$ \\
\hline Monthly $\cos ^{\mathrm{a}}$ (until 2020) & SEK $20,40,60$ \\
\hline
\end{tabular}

${ }^{a} € 1 \approx$ SEK 10 


\subsection{Experimental Design and Data}

Besides the formulation of attributes and attribute levels, the design of a choice experiment needs to consider the explicit variation of attribute levels across and within choice sets, so that the parameters of the econometric model can be identified (Hensher et al. 2001). Based on the results from focus groups and a small pilot study, the design (variation in attribute levels) was made in the software Ngene following a process for "efficient design". Efficiency in this context refers to minimising the predicted standard errors of the parameter estimates. One specific consideration for the Alsterån River Basin was that it is sparsely populated with no large cities. It was not considered feasible to split the sample in blocks as is common to handle a large number of choice sets. The modified Federov algorithm was used to find the most efficient design and a design not characterised by full attribute level balance was finally chosen. ${ }^{3}$ Based on the econometric model, number of choices and priors, Ngene produced a design indicating the lowest possible number of choice sets required to identify parameters and the minimum number of observations needed. In total, eight randomly ordered choice sets were used in the final questionnaire. To avoid forced choices, a status quo alternative - namely As at today - was included in all choice sets. The main concern with forced choices is that respondents may protest and select alternatives while not considering tradeoffs between the attributes, which is of importance for the researcher. To this end, the As at today alternative was characterised by predetermined and fixed attribute levels to reflect the current ecological status of the Alsterån River Basin. Figure 1 presents a sample choice set devised according to the above considerations.

The questionnaire was sent to people living close to the Alsterån River Basin. From a panel of approximately 90,000 randomly phone-recruited Swedish residents (covering the whole country), responses from 502 individuals living in the study area were collected in 2014 (the panel is owned and run by the company Norstat, who also made the sampling and collected the data).

The sampling strategy was somewhat different from traditional mail surveys. Norstat sent out invites to a sample of respondents in their panel and stopped data collection when the demanded number of responses were collected. In this case, a total of 2259 invitations (individual panelists) were sent out before 502 respondents had answered the questionnaire. Given the sampling strategy, this was (according to Norstat) normal although it is not really comparable to traditional response rates.

It is well known that the survey mode may influence the representativeness of samples (Lindhjem and Navrud 2011). In stated preferences studies, such as the present, weak representativeness may potentially translate to biased welfare measures. Still, Internet-based surveys have become the norm and are subject to less scepticism than about a decade ago. The reason for this is basically that the population coverage has improved substantially, and in Sweden, more than $90 \%$ of the population had access to Internet already about fifteen years ago. Still, there are of course issues related to the survey mode, but they are not unique for web-based surveys (see Ek and Persson (2014) for a more extensive discussion about webpanelists). In a panel of respondents, there is a risk of "panel conditioning" meaning that they may be affected by their experience in responding to many other surveys. On the other hand, experienced respondents may deliver more correct and truthful answers (Dillman et al. 2009).

\footnotetext{
${ }_{3}^{3}$ For a more detailed description of the design strategy, see the Ngene Manual available at www.choice-metrics. com.
} 
In respect of the Alsterån River Basin, which of the following alternatives-A, B or C - do you prefer? Note that $\mathrm{C}$ is the current state, and that it has not changed until 2020. Choose one of the options.

\begin{tabular}{|l|l|l|l|}
\hline & Alternative A & Alternative B & $\begin{array}{l}\text { Alternative C } \\
\text { (As at today) }\end{array}$ \\
\hline Water clarity & Clear & Moderate & Moderate \\
\hline Fish - variety of & Moderate & Low & Moderate \\
\hline species & High & Very high & High \\
\hline variety of species & & & 0 \\
\hline Monthly cost & 60 & 60 & {$[$ ] } \\
\hline My choice & {$[\quad]$} & {$[$ ] } & \\
\hline
\end{tabular}

Remember that in all alternatives, characteristics other than those listed are considered unchanged.

Fig. 1 Sample choice set

The respondents were selected to be representative for the population living relatively close to Alsterån, i.e. in municipalities through which the river flows or in municipalities neighbouring those. The geographic stratification was based on the idea of consulting people with some experience and knowledge of the river basin, without focusing only on people living in the immediate vicinity of the river itself or on on-site sampling. By using a somewhat larger geographic area, one is able to capture potential differences in preferences related to the distance to the area. In practice, the choice of geographic area implied a distance to Alsterån of up to around $100 \mathrm{~km}$ for some respondents.

The Alsterån River Basin is located in south-eastern Sweden (see Fig. 2). The relevant catchment area covers $1525 \mathrm{~m}^{2}$, and the flora and fauna in the area are considered rich, see Fig. 2 for a map of the area.

The catchment area ranges across five different municipalities (Högsbo, Kalmar, Mönsterås, Nybro and Uppvidinge) and two regional counties (Kalmar and Kronoberg). Survey responses were selected not only from these five municipalities, but also from six others bordering the catchment area. Thus, a total of 11 municipalities - Emmaboda, Hultsfred, Högsby, Kalmar, Mönsterås, Nybro, Oskarshamn, Lessebo, Uppvidinge, Växjö and Vetlanda were targeted. Their populations ranged between 6000 and 90,000 inhabitants (Statistics Sweden 2017). 


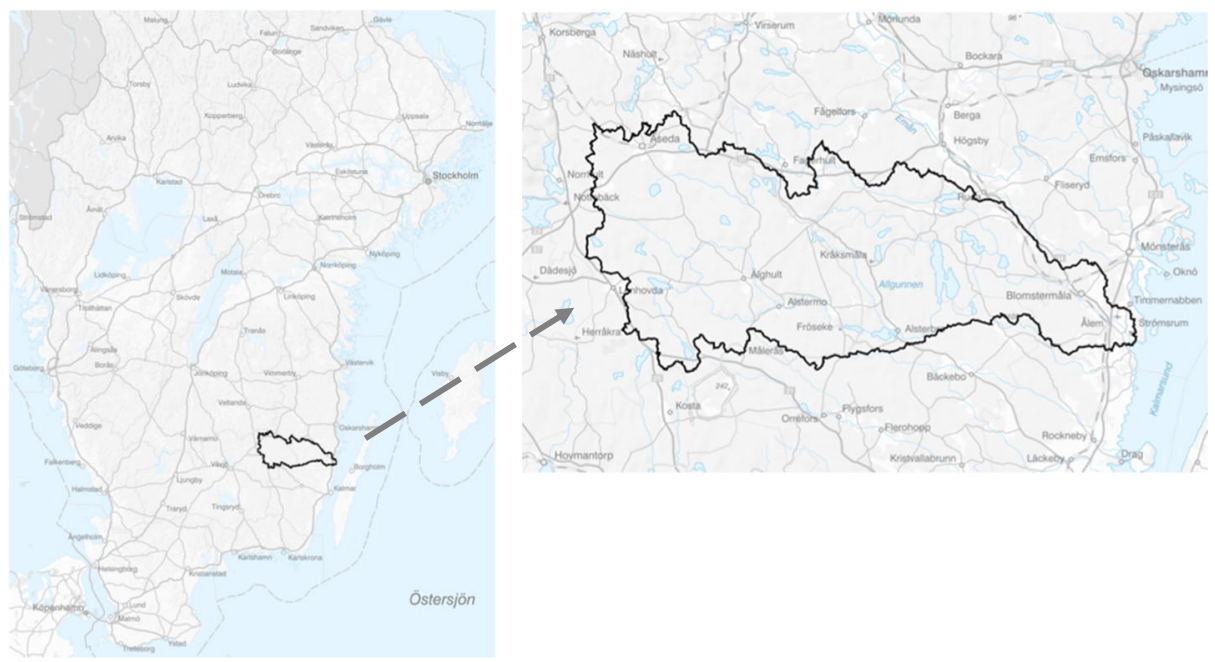

Fig. 2 Map of southern Sweden (left) and the Alsterån River Basin (right)

Most of the municipalities are sparsely populated. For instance, the population density in Högsbo and Uppvidinge is about 8 inhabitants per square kilometre, which is significantly lower than the national average of 25 inhabitants per square kilometre. The average income in all municipalities in the sample is lower than the national average.

The questionnaire consisted of three parts. The first part collected information about respondents' interest in and previous knowledge of water quality in general and in the Alsterån River Basin in particular. The second part introduced the choice experiment. The attributes, each with their respective levels, were repeated briefly before the choice sets. The third and final part of the survey collected socio-economic information. Table 2 presents relevant descriptive statistics for the sample.

The gender distribution across municipalities also varies: the proportion of men is higher in the smaller municipalities but is close to $50 \%$ in the larger municipalities. The average share of men in all 11 municipalities is $51 \%$. The average age of people living in the selected municipalities was 43; older respondents are somewhat overrepresented in the sample, therefore.

Table 2 Descriptive statistics for the study sample

\begin{tabular}{llll}
\hline Variable & & Variable \\
\hline Age (mean) & 49.4 & University edu. (share) & 0.50 \\
Men (share) & 0.53 & Know about Alsterån (share) & 0.41 \\
Children <18 years, Yes (share) & 0.25 & Unemployment (share) & 0.05 \\
Individual monthly income, SEK (mean category) & $20,000-24,999$ & Env. organization (share) & 0.14 \\
Household size (mean) & 2.36 & Dedicated in env. Issues (share) & 0.33 \\
Recreation Alsterån (share) & 0.10 & Pensioner & 0.29 \\
Distance to Alsterån (mean km for those & 54.3 & & \\
$\quad$ who knew about Alsterån) & & & \\
\hline
\end{tabular}




\subsection{Empirical Specification}

In the choice among alternatives, it is assumed that each alternative corresponds to a specific utility level and that the respondent chooses the alternative that provides the highest expected utility. In the econometric specification, this is interpreted as the probability of choosing a specific alternative for the Alsterån River Basin given the attribute levels in the choice set. The analysis of this type of data is typically done within the logit framework. The multinomial logit model (MNL) is based on the rather strong assumption that unobserved factors affecting the choice are strictly independent of each other. To move away from this shortcoming, it is common to apply the random parameter logit (RPL) model (also known as the mixed logit model). The RPL model is more general and less restrictive than the MNL and allows unobserved factors underlying choices to be random and to follow a pre-specified distribution; see e.g. Train (2009). In this study, a RPL specification was used.

In general, individual $q$ 's utility (U) from choosing alternative $j$ in choice situation $t$ can be defined as

$$
\mathrm{U}_{\mathrm{qtj}}=\beta_{\mathrm{q}}^{\prime} \mathrm{X}_{\mathrm{qtj}}+\varepsilon_{\mathrm{qtj}}
$$

where $\mathrm{X}_{\mathrm{qtj}}$ is a vector of observable variables related to the alternative and the respondent. The unobserved parts of eq. (1) are $\beta_{\mathrm{q}}$, which is a vector of coefficients corresponding to the variables (including alternative specific constants, ASC), and $\varepsilon_{\text {jtq }}$, which is the error component. Given this specification, $\beta_{\mathrm{q}}$ represents individual taste among the respondents. In the behavioral process, the respondent knows the utility and the true value of his/her own $\beta_{q}$ and $\varepsilon_{q t j}$ for all $\mathrm{j}$ and chooses the alternative with the highest utility. In the RPL framework, taste is allowed to vary across individuals and the coefficients are characterized by a distribution $f(\beta)$, which is assumed to depend on underlying parameters captured by $\theta$. These underlying parameters could be the mean and the covariance of the distribution. Note that the researcher observes only the variables $X_{\mathrm{qtj}}$ in eq. (1). Hence, assuming that $\beta_{\mathrm{q}}$ is observable and that $\varepsilon_{\mathrm{qjj}}$ is independent and identically distributed (IID) extreme value type 1 , the probability of choosing a given alternative in a choice task would be of a standard logit type. That is, given the values of $\beta_{\mathrm{q}}$ the probability of choosing alternative $j$ is defined by ${ }^{4}$ :

$$
\mathrm{L}_{\mathrm{qj}}\left(\beta_{\mathrm{q}}\right)=\exp \left(\beta_{\mathrm{q}}^{\prime} \mathrm{X}_{\mathrm{qj}}\right) / \sum_{\mathrm{k}} \exp \left(\beta_{\mathrm{q}}^{\prime} \mathrm{X}_{\mathrm{kq}}\right)
$$

However, since $\beta_{\mathrm{q}}$ is unknown (follows a random distribution) it is not possible to use this probability. Instead, the unconditional probability is defined as the integral of $\mathrm{L}_{\mathrm{jq}}\left(\beta_{\mathrm{q}}\right)$ for all possible values of the coefficients,

$$
\mathrm{P}_{\mathrm{q} j}=\int\left(\frac{\exp \left(\beta^{\prime} \mathrm{X}_{\mathrm{qi}}\right)}{\sum_{\mathrm{k}} \exp \left(\beta^{\prime} \mathrm{X}_{\mathrm{kq}}\right)}\right) \mathrm{f}(\beta \mid \theta) \mathrm{d} \beta
$$

Given a specified distribution for the coefficients, the parameters, $\theta$, of the distribution for the coefficients, $f(\beta)$, can be estimated through a simulated maximum likelihood estimator using

\footnotetext{
${ }^{4}$ The panel structure of the data is omitted in the notation for interpretational convenience. It is however taken into consideration in the estimation procedure.
} 
Halton draws (Bhat 2001; Train 2009). As for the choice of distribution, it can take on any distributional form, e.g. normal, lognormal, triangular. In the present study, there is no prior information suggesting any other distribution than the normal form, or similar, which will be the starting point in the estimations.

The RPL specification gives (i) estimates of the coefficients with corresponding standard errors, and (ii) the standard deviation of each random coefficient reflecting preference heterogeneity. Attribute coefficients are given an interpretation analogous to a standard logit and measure the effect on the probability of choosing an alternative (although the absolute numbers require a transformation to be directly comparable). Specific for the RPL, a statistically significant standard deviation means that the coefficient actually varies across individuals and preference heterogeneity is present. This is in contrast to the MNL where the coefficients are assumed to be the same for all individuals in the population and no heterogeneity is accounted for. In the choice experiment, one of the alternatives represents a status quo situation where the attributes illustrate the current situation. This is captured by including a coefficient for the status quo alternative to represent the unobserved sources of utility from maintaining the ecological status of the river basin as it is.

\section{Results}

\subsection{Attitudes Related to Water Quality and Management}

The questionnaire addressed previous knowledge and experience about the river basin, as well as attitudes related to water quality and policy issues in a more general context. Interestingly, $85 \%$ of the respondents reported that they had never given any thought to the water quality in the Alsterån River Basin before joining the survey. This was despite a large proportion of them having been collected from an area that was not only limited geographically, but was also in relative proximity to the river basin. However, the respondents' not having reflected on the basin water's quality is not necessarily a problem for the study, given its purpose to estimate environmental preferences. It rather reflects the limited general public awareness about ecological water quality. This is potentially country specific since water quality is generally high in Sweden. Thus, it is fair to say that water quality is probably not a top priority among environmental issues facing Sweden. This is consistent with results from another question in the survey where respondents reported relatively more concern about the water quality at the European level than at the Swedish level. Almost three quarters of the respondents (74\%) answered "Don't know" when asked about their beliefs about the current environmental status of the river basin. These results are perhaps not surprising considering that the survey approach the general public rather than frequent users or visitors, but they still point at limited knowledge and awareness. A knowledge gap between citizens and experts may challenge the legitimacy of any policy aiming at improving water quality status.

Nonetheless, despite their limited access to information, respondents reported confidence in the effectiveness of policies undertaken to improve water quality. The majority either somewhat or completely agreed with the statement that "Measures that are taken have a large impact on water quality". In addition, almost half of the respondents reported that they were either somewhat or completely confident that policymakers and officials would make the best choice among measures to reach the target of water quality status. They also reported strong preferences for local decision-making (no more centralized than at the county level). 
When choosing across explicit instruments and measures, 54\% preferred regulations, $19 \%$ preferred economic incentives, whereas $14 \%$ stated that they preferred information campaigns as a means to improve water quality. Finally, when asked about how to distribute the costs associated with improving water quality, $43 \%$ agreed that everyone in Sweden should contribute, while $29 \%$ supported the principle of "the polluter pays".

\subsection{The Base Model - Attributes Only}

The estimation starts from the multinomial logit model (MNL) and the random parameter logit (RPL) framework. ${ }^{5}$ These serve as benchmarks for further elaborations. The parameter estimates are presented in Table 3. All attributes, except the cost attribute, are dummy coded to allow for non-linear effects of marginal changes in the attributes.

In the RPL specification, all parameters except the monthly cost attribute are characterized as random parameters with a normal distribution. After testing other distributions (uniform and triangular), the results indicate that there is essentially no difference across distributions (e.g., the likelihood values for the specifications are not statistically different at any relevant level). To compare the RPL and the MNL estimation results, a likelihood ratio test was performed. The result suggests that the RPL specification is preferred over the more restrictive MNL model at the $1 \%$ significance level. Most standard deviations are statistically significant indicating preference heterogeneity in the sample. With respect to signs, the results are similar across specifications, although the statistical significance of some parameter estimates are stronger in the RPL specification. A parameter estimate is interpreted as the impact on the choice probability from a marginal change in the attribute from its base level (here defined as the current level water quality status).

The results from estimating these base models reveal that the level of water clarity in the Alsterån River Basin has a significant impact on the respondents' utility. The parameter estimate for Water clear is positive and statistically significant, while the estimate for Water turbid is negative and statistically significant. Compared to the prevailing level of water clarity, i.e. Moderate, increasing clarity would thus increase utility, while less clarity would reduce utility of the respondents. Also, the variety of fish species affects respondents' well-being: Fish very high and Fish high are positive and statistically significant (although the parameter for Fish high is significant only at the $10 \%$ level). A reduction in the variety of species from Fish moderate to Fish low is negative and statistically significant.

According to these results, the average respondent is willing to pay about 106 SEK per month for improving water clarity (about 10 Euro). The marginal willingness-to-pay (WTP) measures are calculated as the negative ratio of the parameter estimate for the attribute level and the parameter for the cost attribute. For increasing the diversity of fish species in the Alsterån River Basin, respondents are willing to pay 42 SEK per month for achieving Very high and 25 SEK for High levels of diversity of fish species. The results indicate a presence of loss aversion: the WTP to avoid deterioration in the water clarity and in the variety of fish species in the river basin is significantly higher than the WTP for improving these characteristics. All WTP measures should be interpreted as "marginal" since attributes are dummy coded. Nonetheless, although they are "marginal" these measures refer to changes from one attribute level to another.

\footnotetext{
${ }^{5}$ All estimations were done in the NLOGIT 5 software and the cost attribute was scaled down by a factor of 10 .
} 


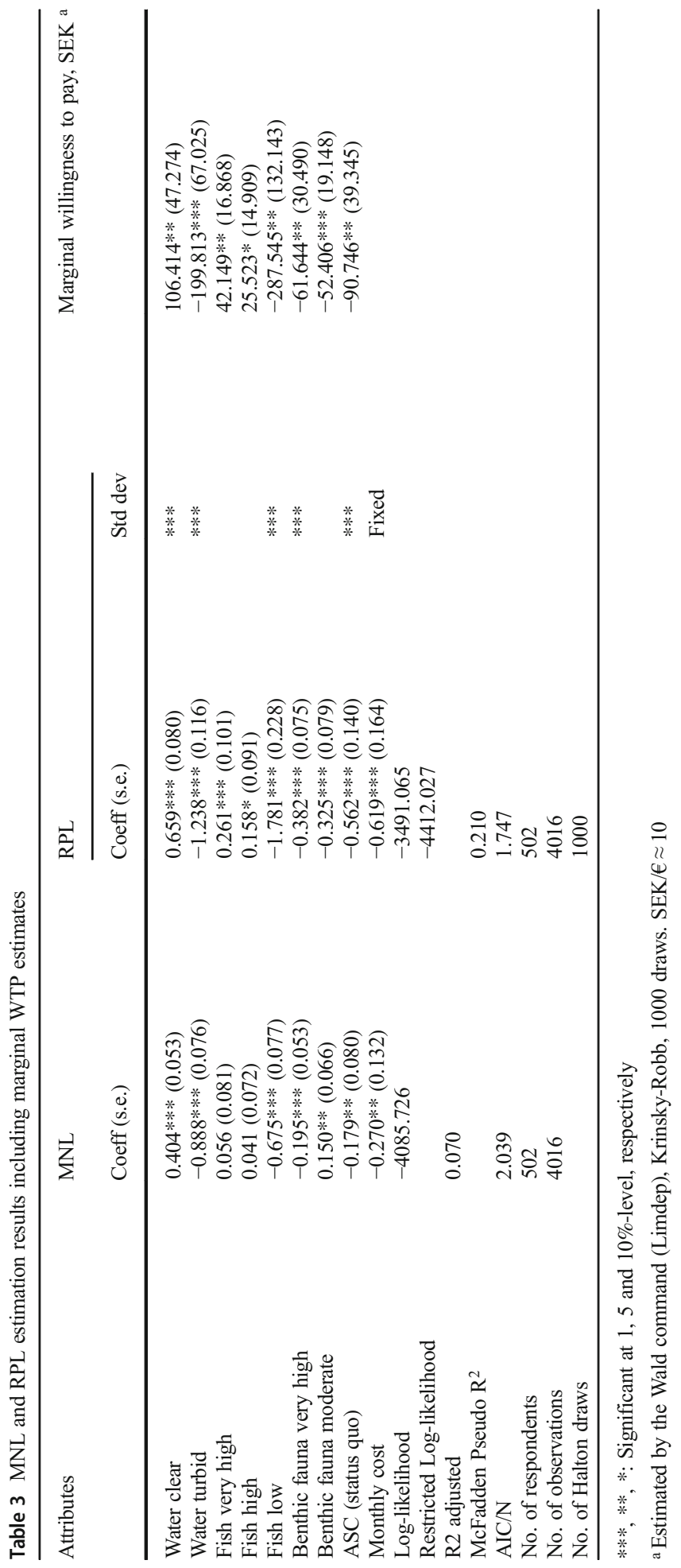


Results regarding the variety of species of the Benthic fauna differ somewhat from water clarity and fish diversity. The benthic fauna parameters indicate that the present High level is preferred over both further improvements to a Very high level, and a deterioration to a Moderate level. Both these parameter estimates are negative and statistically significant. The aversion to increasing benthic fauna is perhaps not that surprising: it is quite reasonable that people would avoid a situation where they saw themselves using a water in a river populated with a very large number of species and microorganisms.

Turning to the ASC (status quo), the results reveal that people generally prefer a change from today's status. The WTP estimate is negative and amounts to about 90 SEK (9 EUR). This is in contrast with any status quo bias (that people in general dislike changes) as the results indicate preferences for a change in the river basin's water quality.

The statistically significant standard deviation for the ASC indicates preference heterogeneity in the choice between the status quo alternative and the other two alternatives.

Finally, the parameter estimate for the Monthly cost is negative and statistically significant, as expected.

\subsection{Who Wants a Change?}

As mentioned in section 3.1, the good good water quality in Sweden overall may explain the somewhat low awareness of, or concern for, water quality issues. Nonetheless, as section 3.2 reveals, there is a rather strong preference for a change, which motivates further elaboration on the potential underlying factors. This section examines what factors that explain the preferences for the status quo alternative vs. the other alternatives. By including a number of status quo constant interaction variables (covariates), we explicitly elaborate on preference heterogeneity. Table 4 presents the results for the variables that proved to explain individual differences in the probability to choose the status quo alternative. ${ }^{6}$

Firstly, the relative sizes, signs and statistical significance of the estimated main effects remain stable if one compares the RPL base model results presented in Table 3 to the extended model results including status quo interaction effects presented in Table 4. Respondents with a more pronounced environmental orientation are less likely to choose the status quo alternative. The parameter estimates for Envorg (Envorg is a dummy variable equal to 1 if the respondent is a member of an environmental organization, 0 otherwise) and Dedicated (which is equal to 1 if the respondent considers him-/herself as being dedicated in environmental issues, 0 otherwise) are both negative and statistically significant. People with a University degree (also a dummy variable) and a higher Age are more likely to choose the status quo alternative than less educated and younger respondents. Respondents with Children in the household are more likely to choose the status quo alternative than people without children in the household (the Children variable is dummy-coded and equal to 1 if there are children younger than 18 in the household, 0 otherwise).

Secondly, although the sample includes people living relatively close to the catchment area, Section 3.1 shows that less than half of the respondents reported being familiar with it. When an evaluation was done as to whether individual differences in previous knowledge about the river basin affected the probability to select the status quo alternative, the results differed from

\footnotetext{
${ }^{6}$ Heterogeneity in preferences have also been analyzed by applying a latent class specification. In contrast to the results reported by e.g., Håkansson et al. (2016) and Kosenius and Ollikainen (2015) the latent class model did not fit our data very well and the results are therefore not presented here.
} 
Table 4 Status quo interactions

Main effects

RPL

Attributes

Water clear

Water turbid

Fish very high

Fish high

Fish low

Benthic fauna very high

Benthic fauna moderate

ASC (status quo)

Monthly cost

Log-likelihood

Restricted Log-likelihood

McFadden Pseudo $\mathrm{R}^{2}$

$\mathrm{AIC} / \mathrm{N}$

No. of respondents

No. of observations

No. of Halton draws

Status quo specific constant interactions

$\begin{array}{lcll}\text { Coeff }(\text { s.e. }) & \text { Std dev } & \text { Interactions } * \text { SQ } & \text { Coeff (s.e.) } \\ 0.648 * * *(0.080) & * * * & \text { Envorg } & -0.562 *(0.316) \\ -1.233 * * *(0.115) & * * * & \text { Dedicated } & -0.522 * *(0.232) \\ 0.262 * * *(0.101) & & \text { University } & 0.422 * *(0.215) \\ 0.160 *(0.091) & & \text { Age } & 0.030 * * *(0.006) \\ -1.760 * *(0.225) & * * * & \text { Children } & 0.529 * *(0.260) \\ -0.374 * * *(0.074) & * & & \\ -0.325 * * *(0.079) & & & \\ -2.125 * * *(0.375) & * * * & & \\ -0.629 * * *(0.164) & \text { Fixed } & & \\ -3475.693 & & & \\ -4412.027 & & & \\ 0.212 & & \\ 1.742 & & \\ 502 & & \\ 4016 & & \\ 1000 & & \end{array}$

***, **, *: Significant at 1,5 and $10 \%$-level, respectively

those of Håkansson et al. (2016), as no statistically significant support for such differences was found. Several other specifications were tested as well, including additional sociodemographic variables (such as gender and income), self-reported recreational habits close to the river basin, and distance of residence from the study area. However, none of these other specifications had a statistically significant impact on the probability of a respondent choosing the status quo alternative; therefore, they are not included in the specifications presented in Table 4. Finally, although several interaction effects were statistically significant, the parameter estimate for the ASC is still characterized by a statistically significant standard deviation, i.e. unexplained preference heterogeneity.

\subsection{Attribute Level Interactions}

The socioeconomic interaction parameter estimates that proved to be statistically significant are presented in Table 5. For convenience, the status quo interactions included in section 3.3 are now discarded. Note that, although only the statistically significant results are presented here, all the interaction variables were tested for all attributes levels.

The only evidence of differences in the preferences for Water clarity with respect to socioeconomic factors was that older people consider Turbid water worse than younger people did. Respondents who considered themselves as being environment-oriented (Dedictated) were more likely to choose alternatives implying improvements in the levels of diversity of Fish species than those who did not.

With regard to the Benthic fauna - variety of species attribute, respondents with a selfreported environmental engagement (Dedicated) were less willing to accept deteriorations in diversify of species of Benthic fauna. Nevertheless, there was no statistically significant evidence that people who consider themselves as environment-oriented (Dedicated) had stronger preferences for improvements in the diversity of benthic fauna than less environment-oriented people. Moreover, respondents claiming to be familiar with the Alsterån 


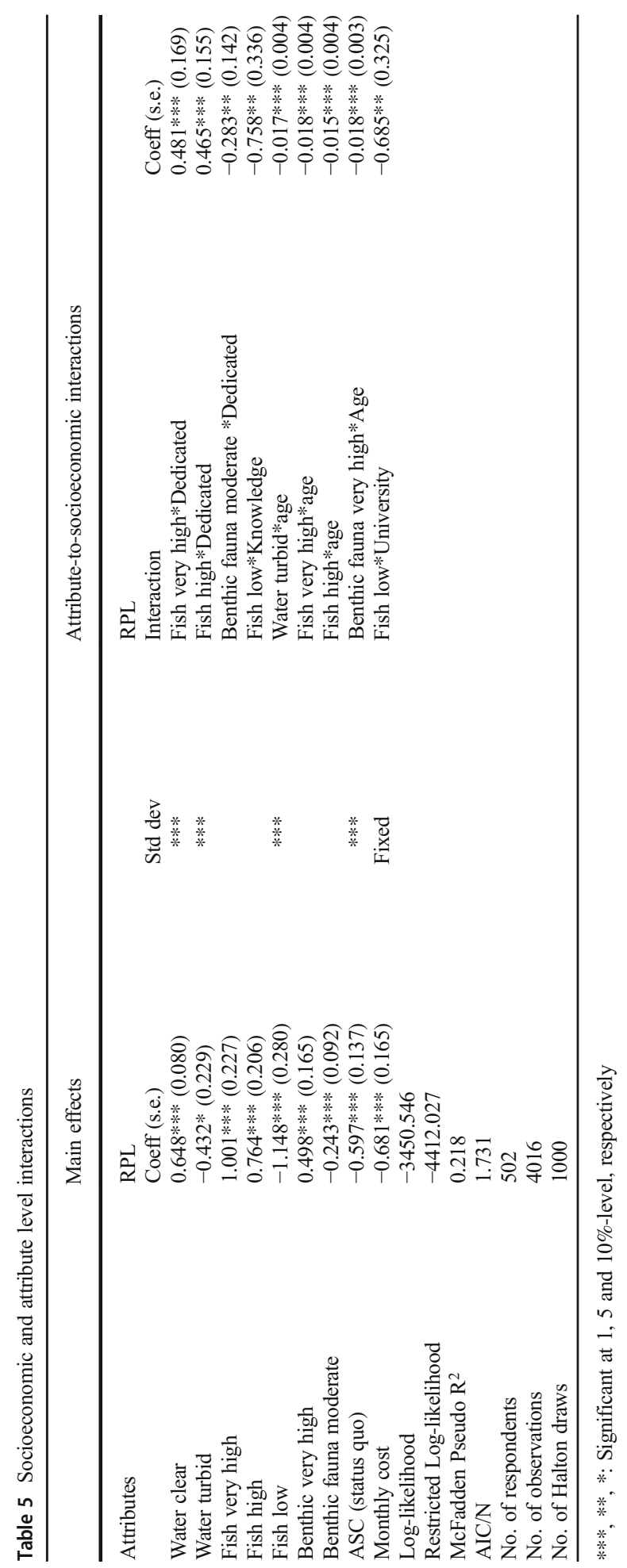


River Basin (Knowledge) and people with higher education (University degree) were less likely to choose alternatives with deteriorations in the diversify with respect to the Fish variety of species attribute. Finally, older respondents were generally less concerned about improvements in the diversity of species of fish or benthic fauna.

Several additional interaction variables were tested as well, such as having children in the household, being a pensioner, being unemployed, making recreational visits in the area (several types of recreation), being a member of an environmental organisation and level of income. However, interacting these variables with the attribute levels did not result in statistically significant parameters.

\section{Concluding Remarks and Policy Implications}

The study analysed the preferences of local and semi-local citizens for water quality attributes related to the implementation of the European Union Water Framework Directive in a river basin in Sweden. A choice experiment approach was applied to elicit respondents' preferences in respect of hypothetical future alternatives representing different states of the river basin's ecological quality. The attributes in the choice experiment were based on versions of actual criteria for water quality used by water managers and officials involved in the implementation of the directive in the catchment area (and elsewhere in Sweden). The attributes characterising each alternative were chosen in close collaboration with public officials involved in water management to reflect realistic and relevant alternatives, both from a policy and an ecological perspective. This is important since the results may help guide policy makers in their prioritisations and tradeoffs across instruments and focus areas when it comes to improving water quality. The sample was selected to be representative of the population living in municipalities through which the river flows, or in municipalities adjacent to them. This made it possible to study potential differences in preferences related to distance to the river basin, knowledge of the basin, recreational habits related to the river, etc.

All selected attributes, namely Water clarity, Fish - variety of species, Benthic fauna variety of species and the Cost attribute, proved to have a statistically significant impact on utility. Increased water clarity was found to be preferred over the present situation, while reducing clarity was considered a change for the worse. These results are in line with our expectations. Moreover, improved variety of fish species would increase utility while reducing fish diversity compared to the present situation would be a change for the worse. These findings are consistent with previous research on the environmental improvements in Swedish rivers (Håkansson 2009; Kataria 2009; Sundqvist 2002), although the findings in the present study are not directly comparable with these previous studies that focused specifically on reducing the negative environmental impact of hydropower generation.

The Fish - variety of species attribute may indicate that preferences for game-fish or similar drives these results, since the level not including game-fish was weaker from a statistic significance perspective. In Water clarity as well as Fish - diversity of species the results showed evidence of loss aversion, in that the marginal WTP to avoid deterioration in the current levels of these two attributes was higher than the willingness to pay for their improvement.

Turning to the Benthic fauna - variety of species attribute, the results suggest that the prevailing status (which corresponds to Good ecological status) was the most preferred, as the parameter estimates for both higher and lower levels of quality were negative. These results are somewhat different from those reported by Kataria (2009), where a positive WTP was 
recorded for improvements in benthic fauna species richness. Still, the current study's design (quality attributes and corresponding levels) and local context differed significantly from those in Kataria's (2009); therefore, any differences in findings should be interpreted carefully. Nonetheless, in general, the WTP measures for changes in attribute levels were consistent with comparable literature in the Swedish context, although the WTP outcomes in the current study were somewhat lower than those found in other similar studies in that context.

As expected, respondents reporting membership in environmental organisations and respondents that consider themselves as engaged in local environmental issues were less likely to opt for the business-as-usual alternative. The latter group also attached higher values to biodiversity than those who did not regard themselves as environmentally engaged. Thus, if the cost for implementing measures to improve ecological water quality would be distributed evenly across residents in the area, those valuing such quality most would also receive the most benefit from an ecological-quality-based water policy.

Although the sample constituted people living in or in relative proximity to the river basin, there are limited indications that distance from, interest in, knowledge about the environmental quality of the river basin, or the recreational habits of the respondents explain heterogeneity in preferences. For example, only the valuation of the Fish - variety of species attribute was found to be different for respondents that had or did not have previous knowledge. Also, respondents claiming to be familiar with the river basin were less likely to choose alternatives that implied a deterioration in the Fish - diversity of species attribute. Moreover, no evidence was found to support the position that that factors related to the respondents' interest, water quality knowledge or recreational habits influenced the probability of their choice of the status quo alternative. This somewhat unexpected lack of significant differences in preferences distinguishes our results from other Swedish cases (Håkansson et al. 2016), and suggests that preferences for ecological water quality, are, to some extent, generic rather than site specific.

Moreover, in light of the emphasis in the directive on the role of public participation, the lack of knowledge and limited interest about issues concerning ecological water status among the respondents may challenge the legitimacy and acceptance of environmental water management. It is possible that people in the area would be reluctant to accept costs for measures aimed towards improved water status, in particular if these are targeted towards increasing the diversity of the benthic fauna.

From a river basin management perspective, the results point at the complexity of making trade-offs in practical decision-making. Clearly, not all attributes are equally important from a societal perspective since, for example, there is a scepticism as regards increasing benthic fauna species on the one hand, with rather strong preferences for clear water and a rich variety of fish species on the other. Although local officials and decision-makers are required to implement the directive, the results from this study may give some guidance as to prioritisations and trade-offs.

As for future research, it would be valuable and interesting to analyse whether preferences differ between public officials, decision makers and the general public, since significant differences in this respect may challenge the legitimacy of policies aiming to improve the ecological status of Sweden's water bodies in accordance with the implementation of the Water Framework Directive.

Acknowledgements Open access funding provided by Luleå University of Technology. Financial support from the Swedish Environmental Protection Agency is gratefully acknowledged. The research undertaken in preparation of this paper was part of the multi-disciplinary research program SPEQS. 


\section{Compliance with Ethical Standards}

Conflict of Interest The authors declare that they have no conflict of interest.

Open Access This article is distributed under the terms of the Creative Commons Attribution 4.0 International License (http://creativecommons.org/licenses/by/4.0/), which permits unrestricted use, distribution, and reproduction in any medium, provided you give appropriate credit to the original author(s) and the source, provide a link to the Creative Commons license, and indicate if changes were made.

\section{References}

Bateman, I.J., Carson, R.T., Day, B., Hanemann, M., Hanley, N., Hett, T., Jones-Lee, M., Loomes, G., Mourato, S., Özdemiroglu, E., Pearce, D., Sugden, R., Swanson, J., 2002. Economic valuation with stated preference surveys: a manual. Edward Elgar

Bhat CR (2001) Quasi-random maximum simulated likelihood estimation of the mixed multinomial logit model. Transp Res 35B(7):677-693

Birol E, Karousakis K, Koundouri P (2006) Using economic valuation techniques to inform water resources management: a survey and critical appraisal of available techniques and an application. Sci Total Environ 365:105-122

Carlsson F, Frykblom P, Liljenstolpe C (2003) Valuing wetland attributes: an application of choice experiments. Ecol Econ 47:95-103

Dillman DA, Smyth JD, Christian LM (2009) Internet, mail, and mixed-mode surveys: the tailored design method. Wiley, Hoboken, NJ

Eggert H, Olsson B (2009) Valuing multi-attribute marine water quality. Mar Policy 33:201-206

Ek K, Persson L (2014) Wind farms - where and how to place them? A choice experiment approach to measure consumer preferences for characteristics of wind farm establishment in Sweden. Ecol Econ 105:193-203

Håkansson C, Östberg K, Bostedt G (2016) Estimating distributional effects of environmental policy in Swedish coastal environments - a walk along different dimensions. Journal of environmental economics and policy $5(1): 49-78$

Hanley N, Colombo S, Tinch D, Black A, Aftab A (2006a) Estimating the benefits of water quality improvements under the water framework directive: are benefits transferable? Eur Rev Agric Econ 33(3):391-413

Hanley N, Wright RE, Alvarez-Farizo B (2006b) Estimating the economic value of improvement in river ecology using choice experiments: an application to the water framework directive. J Environ Manag 78(2):183-193

Hensher DA, Stopher PP, Jordan JJ (2001) An explanatory analysis of the effect of numbers of choice sets in designed choice experiments: an airline choice application. J Air Transp Manag 7(6):373-379

Håkansson C (2009) Costs and benefits of improving wild salmon passage in a regulated river. J Environ Plan Manag 52(3):345-363

Johnston RJ, Duke JM (2007) Willingness to pay for agricultural land preservation and policy process attributes: does the method matter? Am J Agric Econ 89(4):1098-1115

Johnston RJ, Schultz ET, Segerson K, Besedin EY, Ramachandran M (2012) Enhancing the content validity of stated preference valuation: the structure and function of ecological indicators. Land Econ 88(1):102-120

Kataria M (2009) Willingness to pay for environmental improvements in hydropower regulated rivers. Energy Economicis 31:69-76

King, S., Fraser, I., O’Hanley, J.R. 2016. Benefits transfer and the aquatic environment: an investigation into the context of fish passage improvement. Journal of Environmental Management, 1;183(Pt 3):1079-1087

Klauer B, Sigel K, Schiller J (2016) Disproportionate costs in the EU water framework directive - how to justify less stringent environmental objectives. Environ Sci Policy 59:10-17

Kosenius A-K, Ollikainen M (2015) Ecosystem benefits from coastal habitats: a three country choice experiment. Mar Policy 58:15-27

Lehtoranta VO, Kosenius A-K, Seppälä E (2017) Watershed management benefits in a hypothetical, real intention and real willingness to pay approach. Water Resour Manag 31:4117-4132

Lindhjem H, Navrud S (2011) Are internet surveys an alternative to face-to-face interviews in contingent valuation? Ecol Econ 70(9):1628-1637

Loomis JB (2000) Environmental valuation techniques in water resource decision making. Journal of Water Resources Planning and Management 126(6):339-344 
Loomis J, Kent P, Strange L, Fausch K, Covich A (2000) Measuring the total economic value of restoring ecosystem services in an impaired river basin: results from a contingent valuation survey. Ecol Econ 33(1): $103-117$

McGonagle MP, Swallow SK (2005) Open space and public access: a contingent choice application to coastal preservation. Land Econ 81(4):477-495

Mitchell, R.C., Carson, R.T., 1989. Using surveys to value public goods: the contingent valuation method. Washington. Resources for the future

Paulrud A, Laitila T (2013) A cost-benefit analysis of restoring the Em River in Sweden: valuation of angling site characteristics and visitation frequency. Appl Econ 45(16):2255-2266

Samuelsson, K. 2012. Public official involved in water management in Alsterån river basin, county administrative Board in Kalmar. Personal communication. Fall 2012

Statistics Sweden 2017. Internet: http://www.scb.se/hitta-statistik/statistik-efter-amne/befolkning/befolkningenssammansattning/befolkningsstatistik/\#_Tabellerochdiagram. Downloaded May 2017

Sundqvist, T., 2002. Quantifying household preferences over the environmental impacts of hydropower in Sweden: a choice experiment approach. Doctoral thesis: Power generation choice in the presence of environmental externalities

Söderberg C (2016) Complex governance strutures and incoherent policies: implementing the EU water framework directive in Sweden. J Environ Manag 183:90-97

Train KE (2009) Discrete choice methods with simulation, 2nd edn. Cambridge University Press, New York, NY Water Authorities (Vattenmyndigheten Södra Östersjön) (2010) Miljökonsekvensbeskrivning av åtgärdsprogram. Södra Östersjöns vattendistrikt:2009-2015

Zhao M, Johnston RJ, Schultz ET (2013) What to value and how? Ecological indicator choices in stated preference valuation. Environ Resour Econ 56:3-25

Publisher's Note Springer Nature remains neutral with regard to jurisdictional claims in published maps and institutional affiliations. 